\title{
Food taxes and obesity - a literature review
}

\section{Editorial}

Over the past few decades, the world has seen a trend of decreased physical activity and increasing belt sizes. This is a serious matter, because obesity greatly increases the risk of conditions such as diabetes, hypertension, hyperlipidemia, osteoarthritis and coronary artery disease. Part of the problem is diet and particularly processed and high-calorie. After all, obesity occurs when people eat more calories than they expend. The World Health Organization (2008) ${ }^{1}$ recently suggested that governments could use food taxes and subsidies as a financial incentive for people to eat healthier. Of course, such a scheme already exists for tobacco which has been successful in reducing levels of tobacco use. ${ }^{2}$ Whether such a scheme could transfer to food is still open to debate, however. Thus, this literature review will explore the existing research about the following question: Can food tax help reduce obesity levels?

Many studies on this topic use models to predict the effect of food taxes. For example Bahl et al., ${ }^{3}$ produced a model of the Irish economy to predict the effect of changing the price of soft drinks. In Ireland there is already a special tax for soft drinks and the researchers tried to model what would happen if this tax was reduced by $20 \%$. Their model predicted that this would cause a $7 \%$ increase in soft drink consumption in Ireland. In the same year, Santarossa $\&$ Mainland $^{4}$ created a similar model for Scotland. Their model predicted that the price of fatty foods would have to increase by a quarter for fat and energy consumption to fall by $20 \%$ to the government's recommended rates. Four years later, Smed et al., ${ }^{5}$ used a model to examine what would happen if value added tax in the Denmark was halved on vegetables and fruits. They found that sugar consumption in Denmark would reduce by $7 \%$ and saturated fat by $4 \%$. This study and the other two mentioned, all examined the effect of food taxes on consumption. But what about the effect on body weight?

Chouinard et al., ${ }^{6}$ created a model to investigate the relationship between food tax and body weight. They determined that increasing the price of dairy by as much as $50 \%$ would only reduce fat intake from dairy by $3 \%$, which would not be enough to alter body weight. Another study showing that the effects of food taxes are negligible is that of Kuchler et al. ${ }^{7}$ Their model predicted that a $20 \%$ tax on salty foods would reduce calorie intake by only 830 calories per year, which is next to nothing.

Other studies have looked into the link between food taxes and health. One of these is that of Marshall, ${ }^{8}$ who created a model to examine the effect of putting $17.5 \%$ VAT on foods high in saturated fat in the UK. His results claimed that 2,500 deaths a year due to ischaemic heart disease would be prevented if these foods were taxed. Mytton et al., ${ }^{9}$ performed a similar study, but found that VAT on foods high in saturated fat would actually increase deaths, due to people switching to salty foods instead. Mytton et al., ${ }^{9}$ suggested placing VAT on all unhealthy foods, claiming this would reduce deaths by heart disease by around $1.5 \%$ per year. A study by Nnoaham et al., ${ }^{10}$ agreed with these findings, claiming that the best course of action would be to tax unhealthy foods and also to subsidize healthy foods. Another study that showed that benefits of subsidizing healthy foods is that of Cash et al. ${ }^{11}$ They determined that by reducing the price of fruit and

\author{
Volume 2 Issue 3 - 2015
}

\author{
Naif AlEnazi \\ Department of General Surgery, Prince Mohammed bin \\ Abdulaziz Hospital, Saudi Arabia
}

Correspondence: Naif AlEnazi, Department of General Surgery, Consultant Bariatric and Laparoscopic surgery, Prince Mohammed bin Abdulaziz Hospital (PMAH), Riyadh, Kingdom of Saudi Arabia, Email surgeon_n@hotmail.com

Received: April 08, 2015 | Published: April 15, 2015

vegetables by $1 \%$ in the United States, this would save over 10,000 lives a year. However, this would be at a cost of over \$1 million USD per life saved.

Finally, is there a direct link between food taxes and obesity? Asfaw $^{12}$ looked into this topic by using historical data from Egypt. By analyzing the data, Asfaw concluded that sugar and bread subsidies had indeed helped lead to obesity in Egypt and that by removing these subsidies; it would go some way to alleviate the problem. In other words, he claimed that the subsidies have encouraged Egyptians to eat more bread, which is high in calories but low in nutrients, which has contributed to the Egyptian obesity epidemic.

A year earlier, an empirical study into the same topic was performed in the USA by Kim \& Kawachi. ${ }^{13}$ Several USA states already have taxes on unhealthy foods and the researchers looked into whether there is a link between junk food taxes and obesity, by comparing data across the various states of the USA. However, they did not find any relationship between taxes and obesity. And according to Schroeter et al., ${ }^{14}$ taxes on takeaways, fast food and restaurant meals would increase obesity, because people would compensate by eating more food at home.

In summary, many studies have implied that food taxes are indeed able to influence diet and reduce obesity, but then again, many studies have also claimed that food taxes are a waste of effort, because the effects of food taxes are negligible. However, it should be noted that most of these studies only use models, which are not ideal, as their findings are only as valid as the assumptions they are based on. There is certainly a lack of experimental and empirical studies about the topic of food taxes and obesity.

\section{Acknowledgements}

None.

\section{Conflict of interest}

The author declares no conflict of interest.

\section{References}

1. World Health Organization (WHO). 2008-2013 action plan for the global strategy for the prevention and control of noncommunicable diseases. Geneva: World Health Organization; 2008. 
2. Laxminarayan R, Mills AJ, Breman JG, et al. Advancement of global health: key messages from the Disease Control Priorities Project. Lancet. 2006;367(9517):1193-1208.

3. Bahl R, Bird R, Walker MB. The Uneasy Case Against Discriminatory Excise Taxation: Soft Drink Taxes in Ireland. Public Finance Review. 2003;31(5):510-533.

4. Santarossa JM, Mainland DD. Employing an environmental taxation mechanism to reduce fat intake. In: Chern WS, Rickertsen K, editors. Health, nutrition and food demand. 2003. p. 223-245.

5. Smed S, Jensen JD, Denver S. Socio-economic characteristics and the effect of taxation as a health policy instrument. Food Policy. 2007;32(56):624-639.

6. Chouinard HH, Davis DE, LaFrance JT, et al. Fat Taxes: Big Money for Small Change. Forum for Health Economics \& Policy. 2007;10(2):1-30.

7. Kuchler F, Tegene A, Harris J. Taxing snack foods: what to expect for diet and tax revenues. Agric Info Bull. 2005;8:1-11.

8. Marshall T. Exploring a fiscal food policy: the case of diet and ischaemic heart disease. BMJ. 2000;320(7230):301-305.
9. Mytton O, Gray A, Rayner M, et al. Could targeted food taxes improve health? J Epidemiol Community Health. 2007;61(8):689-694.

10. Nnoaham KE, Sacks G, Rayner M, et al. Modelling income group differences in the health and economic impacts of targeted food taxes and subsidies. Int J Epidemiol. 2009;38(5):1324-1333.

11. Cash S, Sunding D, Zilberman D. Fat taxes and thin subsidies: prices, diet, and health incomes. Acta Agriculture Scand Section C. 2005;2:167174

12. Asfaw A. Do Government Food Price Policies Affect the Prevalence of Obesity? Empirical Evidence from Egypt. World Development. 2007;35(4):687-701

13. Kim D, Kawachi I. Food Taxation and Pricing Strategies to "Thin Out" the Obesity Epidemic. American Journal of Preventive Medicine. 2006;30(5):430-437.

14. Schroeter C, Lusk J, Tyner W. Determining the impact of food price and income changes on body weight. Journal of Health Economics. $2008 ; 27(1): 45-68$ 